\title{
Integrity or Compliance Based Ethics: Which Is Better for Today's Business?
}

\author{
Bruce H. Geddes \\ School of Business, Western Governors University, Salt Lake City, USA \\ Email: drbrucegeddes@gmail.com
}

How to cite this paper: Geddes, B.H. (2017) Integrity or Compliance Based Ethics: Which Is Better for Today's Business? Open Journal of Business and Management, 5, 420429.

https://doi.org/10.4236/ojbm.2017.53036

Received: April 26, 2017

Accepted: July 1, 2017

Published: July 4, 2017

Copyright (C) 2017 by author and Scientific Research Publishing Inc. This work is licensed under the Creative Commons Attribution International License (CC BY 4.0).

http://creativecommons.org/licenses/by/4.0/

\begin{abstract}
A firm and a rigorous ethics program are essential in business today. Consumers demand that the companies that they do business with be ethical. Compliance and integrity based ethics programs are the leading pragmatic approaches to ethics used in today's business environment. Reviewing each of these programs individually and then comparing and contrasting them and finally evaluating them as a synthesized program is a useful form of analysis. By separating, then comparing and subsequently integrating the best of both methods leads to the determination that firms must be able to synthesize the two theories and apply them to their business.
\end{abstract}

\section{Keywords}

Ethics, Compliance Based Ethics, Integrity Based Ethics

\section{Introduction}

A successful business and a sound ethical program are not mutually exclusive. The emphasis of this paper will be to examine the differences between integrity based and compliance-based ethics programs. This will be accomplished by detailing the characteristics of each program, synthesizing the program's outcomes, and finally, by looking at how these programs impact business leaders in the current economic climate rife with constant challenges.

\section{A Background in Ethics}

In business today, ethics is one of the most misunderstood yet essential concepts. Topics in business ethics are about questions on whether particular practices are acceptable. The importance of business ethics is a fact that cannot be overshadowed by the vague details that seem to escape an organization that embraces the need for it. Business ethics are controversial and that there is no general phi- 
losophy that will fit all organizations [1].

Ethics in business have never actually been defined. However, the definition of ethics is the structuring of principles with a foundation based on "moral principles, reflective choices, and standards of right and wrong conduct" [1]. As individuals, the people that run businesses today have been exposed to what is considered a right or wrong concept from their parents when they were toddlers. These very concepts become part of an individual's makeup and when they reach the professional level realize that it entails making decisions based on alternative action choices [1].

Today, ethics and the dilemma that ethics imposes in our lives are always being faced by individuals. With the advent of the internet, social media sites, as well as the constant streaming of news; stories of ethical violations are just a mouse click away. However, in 1994 only 13 percent of businesses had any formal ethical codes and only 7 percent of firms offered any training in ethics at all. The more recent times have seen a dramatic change in those statistics with 75 percent of companies now with ethical codes and 40 percent with ethical training programs [1].

\subsection{Compliance Based Ethics}

\subsubsection{Federal Sentencing Guidelines for Organizations (FSGO)}

Compliance based ethics are ethical principles and codes born from government regulations. This is a result of increased illegal practices perpetrated by businesses that were rewarded government contracts in the 1990's. The evolution of government induced ethics dates back to trends starting before the 1980's. For example, in 1977 the Securities and Exchange Commission (SEC) investigated several US companies that bribed foreign officials to procure government contracts. The Foreign Corrupt Practices Act (FCPA) was passed by Congress because of this scandal [2] [3].

President Regan formed the Packard commission that recommended companies adopt an ethics program to lessen exposure to ethical violations and procurement fraud. Continuing the review of the history of compliance-based ethics brings into focus the Savings and Loans scandals of the 1980's which caused the government to pass the Federal Sentencing Guidelines in 1991. This legislation became the foundation upon which compliance regulation was built. The passing of this regulation provided a means to determine the civil penalty to be imposed on a firm convicted of illegal activity [3].

It is important to note that the fines levied in the Federal Sentencing Guidelines were determined in severity of more or less if a company established formal ethics policies, appointed a Compliance Officer, began training in ethics, and made sure a system was in place to monitor these changes, [3]. A business looking to limit expenses would, as a rule of sound business practices, adhere to these guidelines.

Ethics derived from compliance with government regulations lowers ethical expectations of government contracting entities [4]. This serves to create a sort of paper tiger when it comes to organizations that put in place these types of 
ethics programs. However, in 2004 the Federal Sentencing Guidelines were revised to put some teeth into the aforementioned paper tiger.

The 2004 revision of the Federal Sentencing Guidelines was done primarily to foster ethical cultures in businesses as opposed to just technical requirement. The new guidelines required corporations to be not only vigilant about preventing and detecting criminal activity but also to develop an ethical culture [5]. For this reason, it is evident that the government was interested in not just being thought of as dwelling on the low end of ethical code spectrum.

The revised Federal Sentencing Guidelines as are as follows:

1) Corporations must continually assess the risk of criminal conduct occurring.

2) The governing authority (Board of Directors) must be knowledgeable about the compliance and ethics program and take a proactive stance on managing and monitoring it.

3) Ethics and compliance training are mandatory for everyone, including the Board.

4) A whistleblower clause that allows employees to report misconduct without fear of reprisal [9].

The federal government began an initiative in corporate America to reduce federal sentences in criminal prosecution if they increased self-policing by setting up effective, ethical programs. Two principles are the basis for setting up effective, ethical programs (1) the organization must prevent and detect criminal conduct diligently (2) promote and team culture that adheres to ethical conduct and compliance [6].

An organization must meet certain standards to be considered to have complied with the minimum ethics and compliance program, these include:

- Prevention and detection of criminal conduct with rules and policies

- These rules need to be communicated

- An oversight board of the ethics and compliance program

- A corporate compliance officer

- Monitoring and auditing of the ethics compliance program

- Evaluations of the program's effectiveness done on a routine basis

- A whistleblower forum for employees to report without fear of reprisal

- Incentives and discipline to enforce the program

- Once a problem had been identified, countermeasures are to be implemented to prevent a similar occurrence

- Regular evaluation of criminal conduct risk and countermeasures in place to reduce said risks [6].

The FSGO undoubtedly is the benchmark for compliance ethics programs. It's simplistic yet very direct approach to ethics leaves no doubt as to its expectations and criteria. Because of this, the FSGO has had a positive effect on organizations in the business community [6].

\subsubsection{Sarbanes-0xley Act (SOX)}

Corporate fraud scandals of monumental proportion in the early 2000's forced Congress to enact the Sarbanes-Oxley (SOX) act of 2002 to curtail such events of 
fraud and reestablish ethical boundaries for corporations. SOX contains various provisions about corporate ethics. The two provisions designed to address ethics are (1) the development of codes of ethics for corporate executives (2) and the rotation of external auditors on a regular basis [7].

The code of ethics lays the framework for internal governance by highlighting acceptable standards of ethics for a corporation's officers, directors and employees. This entails coverage of the approach from internally. Externally, rotation of the auditors is seen as allowing the auditors to maintain their independence so that they may exercise professional skepticism when it comes to questioning and criticizing business practices. These two standards address what was at the basis of the financial scandals of the early 2000's, that is corporate cultures that had gatekeepers that were so entwined with their careers and finances in these corporations that their professionalism and objectivity were lost. SOX has its critics, however, it has made measurable progress in contributing to a far healthier corporate climate [7].

\subsection{Integrity Based Ethics}

\subsubsection{Integrity Defined}

Integrity is an intricate and important part of all business ethics in which scholars and practitioners confirm that its presence is necessary to attain various ethical goals of business. Integrity is a lot of things to a lot of people and organizations, but its basic premise is based on honesty [6]. Integrity "emphasizes moral consistency, personal wholeness, and honesty" (p. 215). The meaning of integrity is seldom agreed on and sometimes even contradictory in nature [8] [9].

Integrity is defined as "harboring positions of consistency and durability manifested in a correspondence between authentic values, espoused values, and behavior, also persisting in adverse situations" (p. 91) [9]. All in all, it means to define a set of personal values based on honesty and to adhere to these values in all situations regardless of how adversarial an encounter may become.

Yet another definition of integrity based on the Oxford English Dictionary is being and unimpaired state of morality that emphasizes uprightness, sincerity, and honesty. Furthermore, integrity requires a concentrated effort to reconcile several variables and that it is a super virtue represented in thoughts and deeds of those that adhere to the rules [8]. Because of these definitions, it is evident that honesty is at the forefront of integrity and that it becomes the very foundation upon which the construction of an ethics philosophy for businesses can be erected.

\subsubsection{Values Based Decision Making}

An organization must have a mission based on integrity which entails moral commitments and values. Additionally, an organization which recognizes its mission as a way of life and continually strives to adhere to said mission in all respects is arguably the organization that possesses integrity [10]. Organization ethics is framed by Values Based Decision Making (VBDM) [2]. 
Using its Mission statement as its primary guidance in making decisions, VBDM provides a foundation upon which to build a platform, and if implemented successfully, an organizational with integrity will be the results. For an organization to build integrity, there are three conditions that must be adhered to [10]. These are: 1) establish a mission statement; 2) VBDM must be used to make all decisions and policy changes; 3 ) develop a process to navigate through difficult decisions that the organization will invariably face.

Organizational ethics cannot be determined by compliance and integrity forms the basis for comprehension of organizational ethics. To adhere to their integrity values on a consistent basis and conduct themselves in ways that mirror their commitment to fundamentals, firms can use the VBDM approach to ethics [10].

Other researchers concur with establishing values as the fundamental footing upon which to build integrity based ethics. There are four steps in building an integrity based ethics program: 1) ensure the firm's leaders are committed to the ideals; 2) identify what the firm will establish as its core values; 3) train your employees; 4) outline a plan to get ethics engraved in the very fabric of the firm. Successful firms are the ones that can place the greatest emphasis on the fact that ethical behavior is warranted and unethical behavior is discouraged. Incentive programs and evaluations completed annually are two ways to accomplish the goal of continued ethical behavior [11].

\section{A comparison of Integrity Based and Compliance Based Ethics}

\subsection{Ethical Programs Derived from Compliance Regulations}

A compliance based organization is one that establishes rules and conduct with penalties for disobedience. The repercussions of non-compliance keep employees in line. Fear appears to be the driving motivator in the adherence of compliance-based ethics. In American companies, reduced sentencing guidelines were the major factor in adopting ethical programs in nearly all of the Fortune 500 companies. The incentive not to go to jail or to go to jail for less time is a strong motivator to have an ethical program but is certainly not one that will be believed in by employees. This is merely crisis-driven government response in these organizations [8] [12].

Compliance driven ethics programs have long been lauded as just window dressing. The very notion that a firm would adopt an ethics program because it is the right thing to do rather than to be compliant with government regulations and avoid hefty fines is shortsighted. In compliance-based programs, employees are motivated to act out of fear of consequence as opposed to being motivated because of some moral or ethical compass [8] [12].

Ethical programs footed in compliance regulations are moral codes that are adopted by an organization not wanting to face business failure or government fines. Government regulations designed to implore organizations to adopt codes of ethics are reactionary that are Newtonian in form. This Newtonian approach 
was brought on by some public scandal that forced a government reaction; in this case, the mentioned above illegal corporate activities in the 1990's. For this reason, it is clear to see why compliance based ethical programs are referred to as the "low road" method in maintaining an ethical organization [13] [14].

\subsection{Ethical Programs Derived from Integrity Based Programs}

Integrity based ethics programs can be used as a comparison to compliancebased ethics programs. Organizations that have integrity based ethics programs have established core principles that ask everyone to adhere to the principles and govern themselves accordingly. In this instance, employees understand how important the principles are to the mission and the organization's continued success. This understanding comes from a top-down management approach of installing a clear and precise mission statement that employees will buy into [11].

Integrity based ethics programs produce employees that are more prone to being committed to their organizations, more aware in an ethical sense and more willing to report problems ethical in nature. Ethical programs based on integrity allow firms to monitor: employee misconduct, employee comfort levels with reporting misconduct if employees believe they are being treated fairly, and if employees feel pressure to overlook certain matters. From the results of this monitoring system, organizations can identify integrity based ethical related countermeasures that will produce positive results [13].

Another facet of integrity based ethical program is the incentive principles interwoven into the foundation. Rewarding ethical behavior by recognition and financial awards sends a message that ethical behavior is an organization's way of life. In research conducted by Weber and Wasieleski, financial incentives for ethical programs to protect the company from employees of an unethical nature rated 4.1 out of 7 on a Likert scale for importance. That is to say that although money is not the driving force behind integrity based ethical programs, it is a highly sought after incentive [3] [13].

Integrity based ethical programs are not without their detractors. Hartman, argues that an integrity based system can be neutral and allow too much debate without providing a clear direction for employees. Another case in point, is that integrity based programs require training as opposed to just applying a specific set of rules to a situation as in compliance based program. Admittedly, employees have difficulty making ethical choices if they cannot readily identify the ethical choice. Consequently, it is harder for employees to think and consider competing scenarios instead of just applying the rules to the situation [8] [13].

\subsection{Ethics Programs Synthetizing}

A truly effective ethical program will have benchmarks from both compliance and ethically based programs. A more balanced approach with characteristics from compliance and integrity programs is needed. Ethical behavior is not solely good laws or good people but a combination of both [15].

To be more complete, an organization should adopt compliance based codes 
of conduct and from the integrity side a corporate culture that is value based. Effective compliance strategies will see the organization create a code of conduct and successfully communicate the code to its employees. On the same token, the integrity aspect will create a corporate culture where the value of the codes will be revered. The codes specify management's desires; the corporate culture dictates how and when the events occur [15].

The two philosophies of compliance and integrity are at opposites ends of a continuum but should, however, be combined in a complementary manner. Compliance programs are detailed formal rules that individuals choose to adhere to or disobey and commit a violation. Whereas, integrity programs focus on self-control and an internal control function made up of the two components of moral judgment and moral character. Integrity programs aim to build moral character and improve decisions made from an ethical standpoint, and compliance programs include legislation, behavioral codes and control mechanisms [16].

While it is necessary to strike an optimal balance between compliance and integrity driven programs, caution must be acknowledged not to burden the standards with more regulation. Additional regulations or legislation can do more harm than it does good because overregulation is just as bad as under regulation. A risk-based approach to synthesizing the two programs of compliance and integrity is advocated by some [17].

The risk-based approach provides a conceptual framework that emphasizes using the best of both approaches. A business that can understand and manage risk will be able to survive in this globally competitive environment that all businesses operate in today. At its basic level; risk is directly related to ethics when it to comes to uncertainty in decision making [17].

The risk-based approach focuses on (1) create value with good corporate governance (2) respond in a manner that will increase the chance of there being an upside and (3) seize opportunities presented. This approach is to identify and monitor uncertainty. Ethics creates guidelines for appropriate actions and risk management is based on those ethical actions. If an organization is to manage its risk well, then its employees must adhere to good ethics and for an organization to be ethical, its employees must know how to manage risk well [17].

For an organization to be able to strike the optimal balance between the compliance and integrity programs it must learn to balance the following strengths (1) flexibility (2) informing decisions on unexpected issues (3) dialog approach (4) champion teamwork (5) create a dynamic workplace (6) giving the actual values held by the organization (7) feeling of the company belonging to all (8) keep things short and simple (9) allow room for judgment (10) let the outcomes achieved through judgment stand (11) allow outcomes achieved through empowerment to prevail [17].

Often, if there are two prevailing ideologies facing an organization, the astute leaders will use segments of each ideology to obtain a prime result. Compliance necessitates an emphasis on building ethics which is the direction that all organ- 
izations need to be moving in [12].

\subsection{Implications for Business Leaders}

Today, a business that wants to be successful for any length of time must have a competitive advantage. An organization's competitive advantage lies in its strategic resources. An organization that can mesh and implement compliance and integrity based ethics will have a strategic advantage over other businesses in the same industry. "Compliance needs integrity and integrity needs compliance" (p. 31) [18] [19].

An integration of compliance and integrity brings forth a multitude of rewards [8]. Undoubtedly, profit is one of those enhanced rewards received when a business follows some ethical standard. Milton Friedman said that the one responsibility of business is to increase profits, as long as it operated within the rules. The rules in today's global economy are that organizations must adopt ethical standards that make them responsible citizens. There is an overwhelming argument to include ethical decision making in firms as a responsibility. This idea begins at the top, with the leaders of the organizations [20] [21] [22].

Business leaders must find a way to instill ethics in their organization while still maintaining the goal of growing profits on a continuous basis. Business leaders can establish a baseline for ethics in an organization that helps the leader identify areas that can generate ethical outcomes of the positive nature. Leaders can have the greatest impact on organizational culture because of their positions and this, in turn, has the most significant impact on corporate ethics [13].

For and effective, ethical culture to spread throughout the organization, the commitment to ethics must not remain exclusively in the hands of the leader at the top. This responsibility must flow to all the executives and members of management to show an alignment of the message of good ethics, thereby eliminating ambiguity [13].

An effective leader finds a way to make their subordinates want to do the things necessary to achieve the goal set forth by the leader. If the aim is to have an organization that has a foundation in good ethics, then the leader must find a way to make those that follow, want to attain that goal. The more the leader leads by the example of bringing forth ethical internal values as a guiding force, the more trust he/she will generate from his/her followers. This idea will not develop into a blind trust, but the more the leader makes personal sacrifices for the sake of their values, the more the employees are willing to do the same [23].

Ethical leader-follower relationships are a process rather than a flash in the pan one-time event. Merely writing an ethical code is not enough; it must be entrenched into the very fiber of the organization and communicated by the leader continuously. Leaders are the primary force behind the ethical conduct of an organization and are responsible for the guiding their employees in the right direction [23].

Ethics from leaders can be accomplished by a trickle-down effect. That is, top management's ethical leadership has an impact on those at the supervisory level, 
and from that level, it trickles down the employee level. However, leaders can convey the need for ethics to be a part of an employee's life and thereby leading to ethical decision becoming second nature, is the direction in which to move a business. The top leaders in an organization have the broadest impact. It is crucial for business leaders to implement the ethical behavior in their organizations; otherwise, the firm will lose its customers [24].

Ethics and profitability are not mutually exclusive and that it matters to everyone in all walks of life in their personal and professional lives. However, the two are not in competition with each other and that on many occasions the profitable choice is indeed the ethical choice. Ethics is a management tool that has been used to increase productivity and consequently profits in business. Strict adherence to ethical standards increases profits as well as the expansion of business [15] [25].

\section{Conclusion}

This paper set out to define compliance-based ethics and integrity-based ethics individually. Once established, a comparison was drawn between the two philosophies and the two views were subsequently synthesized together and looked at from the perspective of one all-inclusive philosophy. The meaning of what the two philosophies meant to business leaders was discussed next and also how a company should draw from the best of both themes to create an ethics based, profit generating, successful business. While there is evidence of ethics being linked to profitability, the need for further research is warranted to answer the question of whether an organization which chooses the ethical road on which to conduct business will be rewarded with continued success and be viewed as good corporate citizens of the world.

\section{References}

[1] Onyebuchi, V.N. (2011) Ethics in Accounting. International Journal of Business and Social Science, 2.

http://search.proquest.com.library.capella.edu/docview/904512723? accountid=27965

[2] Roberts, R. (2009) The Rise of Compliance-Based Ethics Management. Public Integrity, 11, 261-277. https://doi.org/10.2753/PIN1099-9922110305

[3] Weber, J. and Wasieleski, D.M. (2013) Corporate Ethics and Compliance Programs: A Report, Analysis and Critique. Journal of Business Ethics, 112, 609-626. https://doi.org/10.1007/s10551-012-1561-6

[4] Roberts, R. (2009) The Rise of Compliance-Based Ethics Management. Public Integrity, 11, 261-277. https://doi.org/10.2753/PIN1099-9922110305

[5] Hess, D., McWhorter, R.S. and Fort, T.L. (2006) THE 2004 Amendments to the Federal Sentencing Guidelines and Their Implicit Call for a Symbiotic Integration of Business Ethics. Fordham Journal of Corporate \& Financial Law, 11, 725-764.

[6] Hopkins, S.L. (2013) How Effective Are Ethics Codes and Programs? Financial EXecutive, 29, 42-45.

[7] Orin, R.M. (2008) Ethical Guidance and Constraint under the Sarbanes Oxley Act of 2002. Journal of Accounting, Auditing \& Finance, 23, 141-171. 
[8] Jacobs, D.C. (2004) A Pragmatist Approach to Integrity in Business Ethics. Journal of Management Inquiry, 13, 215-223. https://doi.org/10.1177/1056492604268203

[9] Tullberg, J. (2012) Integrity-Clarifying and Upgrading an Important Concept for Business Ethics. Business \& Society Review, 117, 89-121. https://doi.org/10.1111/j.1467-8594.2011.00401.x

[10] Ana, S.I. (2005) Values Based Decision Making: Organizational Mission and Integrity. HEC Forum, 17, 6-17. https://doi.org/10.1007/s10730-005-4947-3

[11] Hartman, L. (2000) Compliance versus Integrity: The Process of Ethics Integration. Journal of Employment Discrimination Law, 2, 157-159.

[12] Bandsuch, M., Pate, L. and Theies, J. (2008) Rebuilding Stakeholder Trust in Business: An Examination of Principle-Centered Leadership and Organizational Transparency in Corporate Governance. Business \& Society Review, 113, 99-127. https://doi.org/10.1111/j.1467-8594.2008.00315.x

[13] Lager, J.M. (2010) Governments Demand Compliance, Ethics Demands Leadership. Journal of Public Affairs, 10, 216-224. https://doi.org/10.1002/pa.361

[14] Roberts, R. (2009) The Rise of Compliance-Based Ethics Management. Public Integrity, 11, 261-277. https://doi.org/10.2753/PIN1099-9922110305

[15] Eliason, M.J. (1999) Compliance plus Integrity. The Internal Auditor, 56, 30-33.

[16] Maesschalck, J. (2004) Approaches to Ethics Management in the Public Sector. Public Integrity, 7, 21-41.

[17] Arjoon, S. (2006) Striking a Balance between Rules and Principles-Based Approaches for Effective Governance: A Risks-Based Approach. Journal of Business Ethics, 68, 53-82. https://doi.org/10.1007/s10551-006-9040-6

[18] Doris, G.O. and Rune, E.G. (2011) Knowledge Resources and Competitive Advantage. Managing Global Transitions, 9, 335-354.

[19] Thielemann, U. (2005) Compliance und Integrity-Zwei Seiten Ethisch Integrierter Unternehmenssteuerung. Zeitschrift Fuer Wirtschafts-Und Unternehmensethik, 6, $31-45$

[20] Mercia, S. and Malar, S. (2008) The "Ethics" of Being Profit Focused. Social Responsibility Journal, 4, 136-142. https://doi.org/10.1108/17471110810856901

[21] Schwartz, M.S. and Saiia, D. (2012) Should Firms Go 'Beyond Profits'? Milton Friedman versus Broad CSR1. Business \& Society Review, 117, 1-31. https://doi.org/10.1111/j.1467-8594.2011.00397.x

[22] Dipasri, G., Dilip, K., Ghosh, A. and Abdel, Z. (2011) Business, Ethics, and Profit: Are They Compatible under Corporate Governance in Our Global Economy? Global Finance Journal, 22, 72-79. https://doi.org/10.1016/j.gfj.2011.05.006

[23] Mihelic, K.K., Msc, L.B. and Tekavcic, M. (2010) Ethical Leadership. International Journal of Management and Information Systems, 14, 31-41. https://doi.org/10.19030/ijmis.v14i5.11

[24] Ruiz, P., Ruiz, C. and Martínez, R. (2011) Improving the "Leader-Follower" Relationship: Top Manager or Supervisor? The Ethical Leadership Trickle-Down Effect on Follower Job Response. Journal of Business Ethics, 99, 587-608. https://doi.org/10.1007/s10551-010-0670-3

[25] Ghosh, D., Ghosh, D.K. and Zaher, A.A. (2011) Business, Ethics, and Profit: Are They Compatible under Corporate Governance in Our Global Economy? Global Finance Journal, 22, 72-79. https://doi.org/10.1016/j.gfj.2011.05.006 
Submit or recommend next manuscript to SCIRP and we will provide best service for you:

Accepting pre-submission inquiries through Email, Facebook, LinkedIn, Twitter, etc. A wide selection of journals (inclusive of 9 subjects, more than 200 journals)

Providing 24-hour high-quality service

User-friendly online submission system

Fair and swift peer-review system

Efficient typesetting and proofreading procedure

Display of the result of downloads and visits, as well as the number of cited articles Maximum dissemination of your research work

Submit your manuscript at: http://papersubmission.scirp.org/

Or contact ojbm@scirp.org 